\title{
SYSTEMIC BLOOD PLASMA CCL5 AND CXCL6: POTENTIAL BIOMARKERS FOR HUMAN LUMBAR DISC DEGENERATION
}

\author{
S. Grad ${ }^{1,2, \$ *}$, C. Bow 3 , J. Karppinen ${ }^{2,4,5}$, K.D.K. Luk ${ }^{3}$, K.M.C. Cheung ${ }^{2,3}$, M. Alini ${ }^{1,2}$ and D. Samartzis ${ }^{2,3, \S}$
}

\author{
${ }^{1}$ AO Research Institute Davos, Davos, Switzerland \\ ${ }^{2}$ AOSpine Research Network, Davos, Switzerland \\ ${ }^{3}$ Department of Orthopaedics and Traumatology, The University of Hong Kong, Hong Kong, SAR, China \\ ${ }^{4}$ Center for Life Course Epidemiology and Systems Medicine, Research Center Oulu, Oulu University Hospital and University of \\ Oulu, Oulu, Finland \\ ${ }^{5}$ Finnish Institute of Occupational Health, Health and Work Ability, Oulu, Finland
}

${ }^{\S}$ These two authors contributed equally.

\begin{abstract}
Lumbar disc degeneration severity on magnetic resonance imaging (MRI) is associated with low back pain. Proinflammatory chemokines CCL5 and CXCL6 are released by induced degenerative discs, and CCL 5 has been associated with discogenic back pain. A case-control study was performed, based on the Hong Kong Disc Degeneration Population-Based Cohort of Southern Chinese, to investigate if systemic levels of CCL5 and CXCL6 were elevated in subjects with disc degeneration compared to non-degenerated individuals. Eighty subjects were selected, 40 with no disc degeneration (control group; DDD score 0) and 40 with moderate/severe disc degeneration (disc degeneration group; DDD score $\geq 5$ ) as noted on MRI. Subjects were matched for age, sex, body mass index and workload. Blood plasma samples were obtained from each individual, and levels of CCL5 and CXCL6 were measured. Secondary phenotypes of lumbar disc displacement and cervical disc changes were also assessed. CCL5 concentrations were significantly increased in the disc degeneration (mean: $19.8 \mathrm{ng} / \mathrm{mL}$ ) compared to the control group (mean: $12.8 \mathrm{ng} / \mathrm{mL})(p=0.015)$. The degeneration group demonstrated higher levels of CXCL6 (mean: $56.9 \mathrm{pg} / \mathrm{mL}$ ) compared to the control group (mean: $43.4 \mathrm{pg} / \mathrm{mL})(p=0.010)$. There was a trend towards elevated CCL5 levels with disc displacement in the degeneration group $(p=0.073)$. Cervical disc degeneration was not associated with elevated chemokine levels $(p>0.05)$. This is the first study to note that elevated systemic CCL5 and CXCL6 were associated with moderate/severe lumbar disc degeneration, further corroborating tissue studies of painful discs. These chemokines may be systemic biomarkers for the diagnosis and monitoring of disc degeneration.
\end{abstract}

Keywords: Intervertebral disc, degeneration, biomarker, CCL5, CXCL6, magnetic resonance imaging.

*Address for correspondence:

Sibylle Grad

AO Research Institute Davos

Clavadelerstrasse 8, 7270 Davos, Switzerland

E-mail 1: sibylle.grad@aofoundation.org

Telephone Number: +41 814142480

FAX Number: +41814142288

Email 2: dsamartzis@msn.com

Telephone Number: (+852) 2255-4654

FAX Number: (+852) 2817-4392
Low back pain (LBP) is the world's most disabling condition (Vos et al., 2012), representing a substantial socioeconomic and health-care burden (Dagenais et al., 2008). Although the aetiology of LBP is multifactorial, intervertebral disc degeneration has been noted to be a determinant (Andersson, 1999; Shen et al., 2006). However, diagnostics of discogenic-related LBP can be tenuous and previous methods, such as discography, are questionable and may have complications (Carragee et al., 2009).

Magnetic resonance imaging (MRI) is a non-invasive modality that allows assessment of the soft tissue structures of the spine, in particular the disc that may otherwise be undetected using x-rays. Previous studies have noted that a relationship between disc degeneration and LBP is a coincidental finding and that the predictive capacity of MRI in terms of LBP is questionable (Boden et al., 1990; Borenstein et al., 2001; Jensen et al., 1994). However, more recent studies, taking into account specific phenotypes of disc degeneration and based on large populations, have noted a significant association between more moderate and severe forms of degeneration to that of LBP and the predictive capacity of developing more pain severity (Cheung et al., 2009; Samartzis et al., 2011; Takatalo et al., 2011). Nonetheless, traditional MRI sequences (e.g. T1- or T2-weighted) are not without limitations, as they fail to identify specific biochemical changes of the disc, disease activity and severity of symptoms (Chou et al., 2011; Fenty et al., 2013; Lotz et al., 2012; Zhang et al., 2009). This may account for some of the tenuous outcomes that accompany spinal fusion procedures or other conservative therapeutics for the disc, the inability to correctly identify early disc changes, and discogenic origins of LBP (Deyo et al., 2005; Fritzell et al., 2002; Rajaee et al., 2011).

Damage to the disc can induce an inflammatory response involving the production of cytokines and growth factors (Burke et al., 2002; Freemont, 2009). There is increasing evidence that this inflammatory response is the main pathological reason for the occurrence of discogenic LBP (Wuertz and Haglund, 2013). Furthermore, damaged discs are also characterised by increased vascularity, facilitating leakage of inflammatory molecules into the circulation. Studies have reported that circulating levels of high-sensitivity C-reactive protein and various interleukins (e.g. IL-6, IL-8) were elevated in patients with chronic LBP and may even serve as markers for prognosticating pain relief (Rannou et al., 2007; Rathod et al., 2014; Roy 
et al., 2010). Moreover, matrix metabolism biomarkers suggest differences in the pathological process of disc space narrowing and osteophyte formation (Goode et al., 2012). While certain markers of matrix turnover and inflammation are likely to be identical in intervertebral disc and other diseases, there might also be particular molecules that are predominantly released by damaged discs. Therefore, molecular pathological factors associated with disc degeneration may provide additional information to the imaging observations and contribute to better understanding of true discogenic origins of LBP and insights into devising more "precise" and "personalised" therapeutics for the patient (Samartzis et al., 2015). Furthermore, identifying such reliable molecular "biomarkers", for example by blood assessment, may decrease costs associated with expensive imaging, such as MRI, that may also not be readily available in many parts of the world.

Using an in vitro organ culture model, we have shown that mesenchymal stem cell (MSC) homing in induced degenerative discs was mediated by chemoattractants that were released by the damaged disc cells (Illien-Junger et al., 2012). Further studies revealed that the chemokines $\mathrm{C}-\mathrm{C}$ motif ligand 5 (CCL5) and C-X-C motif ligand 6 (CXCL6) were released into conditioned medium of induced degenerative discs in organ culture (Pattappa et al., 2014). Interestingly, CCL5 has also been detected in human degenerative disc tissue and appears to play a role in painful disc disorders (Kepler et al., 2013; Pattappa et al., 2014). Therefore, CCL5 and CXCL6 may be candidate markers to determine the degenerative state of the disc, improve our understanding of discogenic pain subtypes, and potentially monitor patient management/therapeutics. As such, the aim of this study was to compare systemic blood plasma concentrations of CCL5 and CXCL6 in human subjects with no disc degeneration to those with moderate/severe forms of disc degeneration on MRI. We hypothesised that levels of CCL5 and CXCL6 would be elevated in the peripheral blood of patients with disc degeneration compared to physiological levels of subjects without disc changes.

\section{Methods}

\section{Study subjects}

This was a case-control study whose subjects were sampled from the Hong Kong Disc Degeneration Population-Based Cohort of Southern Chinese (Cheung et al., 2012; Cheung et al., 2010; Mok et al., 2010; Samartzis et al., 2012; Samartzis et al., 2011; Song et al., 2008). This cohort is currently composed of approximately 3,500 volunteer subjects (age range: 10-88 years), who were recruited by open invitation to assess disc degeneration on MRI in congruence with risk factors and clinical profile in association with their degenerative status. None of the subjects were recruited based on their pain phenotype. Institutional review board approval was obtained by each subject enrolled in this study. The recruitment protocol has been previously noted elsewhere and previous studies have shown the cohort to be representative of the population (Cheung et al., 2012; Cheung et al., 2010; Mok et al.,

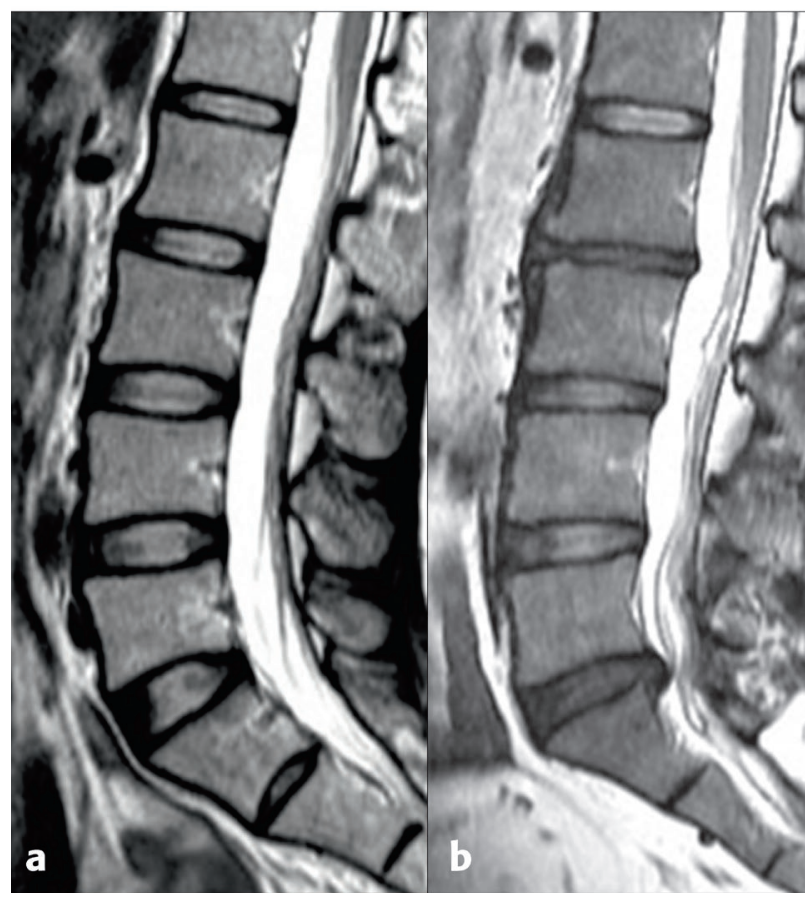

Fig. 1. Sagittal lumbar MRIs of subjects with (a) no disc degeneration (control group) and (b) moderate/severe disc degeneration (degeneration group).

2010; Samartzis et al., 2012; Samartzis et al., 2011; Song et al., 2008).

\section{Imaging assessment}

All subjects underwent whole spine T2-weighted sagittal MRI without fat suppression. The MRI protocol was as follows: $5 \mathrm{~mm}$ slice thickness, $1 \mathrm{~mm}$ slice gap, FOV of $280 \mathrm{~mm} \times 240 \mathrm{~mm}$, and a matrix of $448 \times 336$. MRIs of the spine were assessed and the discs of the lumbar spine (L1-S1) were graded based on the Schneiderman et al. (1987) radiographic classification for disc degeneration (Fig. 1a and 1b). This grading scheme ranged from 0 to 3 and was defined as follows: no degeneration denoted by high signal intensity of the disc $($ score $=0)$; mild degeneration with slight decrease in signal intensity of the nucleus pulposus (score $=1$ ); moderate degeneration with generalised hypointensity of the nucleus pulposus (black disc) with normal disc height (score $=2$ ); and severe degeneration (black disc) with disc height narrowing (score $=3$ ). Based on this classification scheme, each of the five lumbar discs was assigned a grade (potential range: 0 to 3 ). The individual five disc grades were then summated to obtain a global severity of disc degeneration score of the lumbar spine, otherwise known as the Degenerative Disc Disease (DDD) Score (potential score range: 0 to 15). As a secondary phenotype of the disc proper, the presence of lumbar disc displacement was also assessed and noted as any presence of posterior disc bulge, protrusion or extrusion (Fardon et al., 2014). No sequestration of disc material was noted in this study sample. Furthermore, the presence of cervical disc degeneration, such as decreased disc space height, osteophyte formation, disc herniations, was also noted. Reliability of the scoring protocol has been previously reported and was noted to be excellent (Cheung et al., 2009; Mok et al., 2010). 
Selection of non-degenerated and degenerated groups Based on previous studies of the DDD score and LBP, it was noted that moderate/severe lumbar disc degeneration (DDD score $\geq 5$ ) was significantly associated with a history of LBP (Cheung et al., 2009; Samartzis et al., 2011; Takatalo et al., 2011). As such, 40 individuals were selected as cases with no disc degeneration representing the control group $($ DDD score $=0)$ and 40 individuals were identified as cases representing the disc degeneration group (DDD score $\geq 5$ ). Since disc degeneration and LBP are multifactorial based on several modifiable and non-modifiable risk factors (Andersson, 1999; Samartzis et al., 2012; Samartzis et al., 2011; Shen et al., 2006), the cases and controls were matched for sex, age, body mass index $\left(\mathrm{BMI} ; \mathrm{kg} / \mathrm{m}^{2}\right)$, and workload at the time of MRI and blood extraction. Physical workload was assessed based on the individuals' current occupation history, noted as sedentary (score 0 ), light (score 1), medium (score 3), heavy (score 4) or very heavy (score 5) for each individual. Furthermore, none of these subjects had current spine fractures, tumours, metabolic disorders, or progressive inflammatory disease.

\section{Blood collection and CCL5/CXCL6 analysis}

Around the time of imaging, peripheral blood was collected from each subject. Blood samples were obtained in the morning, and all individuals were fasting and at rest at time of blood collection. Blood was collected in tubes containing ethylenediaminetetraacetic acid (EDTA) as an anticoagulant and the tubes were centrifuged for $15 \mathrm{~min}$ at $1000 \times g$ within $30 \mathrm{~min}$ of collection. Resulting blood plasma samples were stored at $-80^{\circ} \mathrm{C}$. Concentrations of CCL5 and CXCL6 in all plasma samples were quantified in duplicates after appropriate dilution using commercially available ELISA systems (Quantikine, R\&D Systems, Minneapolis, MN, USA). Quantitative values for CCL5 and CXCL6 were noted in $\mathrm{ng} / \mathrm{mL}$ and $\mathrm{pg} / \mathrm{mL}$, respectively.

\section{Statistical analysis}

All data were obtained and entered upon a spreadsheet. SPSS version 21 (Chicago, IL, USA) was used to conduct descriptive and analytical analyses. Descriptive analyses were performed of all the data points. Chi-square tests were utilised to assess the difference between categorical variables. Independent sample $t$-tests were utilised to assess the mean difference and $95 \%$ confidence intervals (CI) between the control and degenerative groups with regards to subject characteristics and chemokine levels for continuous variables. Receiver operating characteristic (ROC) curve analyses was also performed to determine the area under the curve (AUC) of chemokine levels to that of lumbar disc degeneration. Power analyses were also conducted based on the mean difference and standard deviations between both CCL5 and CXCL6 in relation to group-type with an alpha value of 0.05 . Statistical power of 0.90 or greater was considered excellent (Vavken et al., 2015). Furthermore, for secondary phenotype analyses, if the data distribution deemed so, multivariate analyses were performed taking into account the covariates of age, sex, BMI and workload. The threshold for statistical significance was established at $p<0.05$. Precision was also assessed based on $95 \%$ CI bounds.

\section{Results}

Blood plasma concentrations were assessed in all 80 subjects. Each of the groups had 26 females and 14 males $(p=1.000)$. The mean ages for the control and disc degeneration groups were, 49.2 y (SD: \pm 5.8 ; range: 34.3-58.8 y) and 49.5 y (SD: \pm 5.9 ; range: 34.1-58.5 y), respectively ( $p=0.853)$. The mean BMIs for the control and disc degeneration groups were $23.3 \mathrm{~kg} / \mathrm{m}^{2}$ (SD: \pm 2.6 ; range: $\left.18.2-30.1 \mathrm{~kg} / \mathrm{m}^{2}\right)$ and $23.4 \mathrm{~kg} / \mathrm{m}^{2}(\mathrm{SD}: \pm 2.7$; range: $\left.18.6-31.3 \mathrm{~kg} / \mathrm{m}^{2}\right)$, respectively $(p=0.885)$. The control group had no disc degeneration (DDD score $=0$ ), whereas the degeneration group had a mean DDD score of 6.6 (SD: \pm 2.0 ; range: $5-12)(p<0.001)$. In the disc degeneration group, most of the disc degeneration was noted in the lower lumbar spine (i.e. L4-S1), affecting $95.0 \%$ of the discs. Overall disc displacement was noted only in the disc degeneration group, occurring in $62.5 \%$ of the subjects $(n=25)$. Cervical disc changes were noted in $32.5 \%$ of the control group compared to $46.2 \%$ in the lumbar disc degeneration group $(p=0.214)$. Patient characteristics are summarised in Table 1.

The overall CCL5 and CXCL6 blood plasma concentrations were $16.3 \mathrm{ng} / \mathrm{mL}(\mathrm{SD}: \pm 13.0$; range: 2.1-63.8 $\mathrm{ng} / \mathrm{mL}$ ) and $50.2 \mathrm{pg} / \mathrm{mL}(\mathrm{SD}: \pm 23.5$; range: 16.7-150.5 pg/mL), respectively (Table 1). CCL5 blood plasma concentrations were significantly increased in the disc degeneration group (mean: $19.8 \mathrm{ng} / \mathrm{mL}$; $95 \% \mathrm{CI}$ : $14.7-25.0 \mathrm{ng} / \mathrm{mL}$ ) compared to the control group subjects (mean: $12.8 \mathrm{ng} / \mathrm{mL} ; 95 \%$ CI: $10.3-15.2 \mathrm{ng} / \mathrm{mL})(p=0.015)$ (Fig. 2a). Similarly, CXCL6 blood plasma concentrations were significantly higher in the disc degeneration group (mean: $56.9 \mathrm{pg} / \mathrm{mL}$; $95 \% \mathrm{CI}$ : 48.5-65.3 pg/mL) compared to the levels of the control group (mean: $43.4 \mathrm{pg} / \mathrm{mL}$; $95 \%$ CI: $37.5-49.3 \mathrm{pg} / \mathrm{mL})(p=0.010)$ (Fig. $2 \mathrm{~b})$. When focussing at different lumbar levels of the spine from L1S1, specifically looking at high, mid and lower lumbar regions in individuals with noted degenerated disc changes on MRI, CCL5 and CXCL6 concentrations did not vary between different degenerated levels (L1-S1) of the lumbar spine $(p>0.05)$. Based on ROC analyses, AUCs for CCL5 and CXCL6 were 0.61 (95\% CI: 0.48-0.74) and 0.67 (0.55-0.78), respectively (Fig. 3).

With regards to the secondary phenotype of disc displacement noted in the disc degeneration group, no statistically significant difference was noted based on the sample size between the presence or not of disc displacement to that of CXCL6 $(p=0.597)$; however, a suggestive trend towards significance was noted with elevated levels of CCL5 in subjects with disc displacement (mean: 23.4 vs. $14.0 \mathrm{ng} / \mathrm{mL} ; p=0.073$ ). All subjects with disc displacement had some degree of disc degeneration. No statistical difference was noted between cervical disc changes and chemokine levels $(p>0.05)$. Since we did not find any significance in the relation between chemokine levels and cervical disc changes, cases that had cervical changes were not excluded from the overall evaluation. Based on the findings, the statistical powers for the CCL5 and CXCL6 chemokine assessments were considered excellent with values of 0.98 and 0.99 , respectively, in relation to assessing the difference between non-disc 
Table 1. Characteristics of the study subjects.

\begin{tabular}{|c|c|c|c|}
\hline & $\begin{array}{c}\text { Control Group } \\
n=40 \\
\end{array}$ & $\begin{array}{c}\text { Disc Degeneration Group } \\
n=40\end{array}$ & $p$ value \\
\hline Females $\dagger$ & $65 \%$ & $65 \%$ & 1.000 \\
\hline Age (years) & $\begin{array}{c}49.2( \pm 5.8) \\
34.3-58.8\end{array}$ & $\begin{array}{c}49.5( \pm 5.9) \\
34.1-58.5\end{array}$ & 0.853 \\
\hline Body mass index $\left(\mathrm{kg} / \mathrm{m}^{2}\right)$ & $\begin{array}{c}23.3( \pm 2.6) \\
18.2-30.2\end{array}$ & $\begin{array}{c}23.4( \pm 2.7) \\
18.6-31.3\end{array}$ & 0.885 \\
\hline Workload & $\begin{array}{c}1.4( \pm 0.6) \\
0-2\end{array}$ & $\begin{array}{c}1.6( \pm 0.7) \\
1-4\end{array}$ & 0.383 \\
\hline Lumbar DDD score & 0 & $\begin{array}{c}6.6( \pm 2.0) \\
5-12\end{array}$ & $<0.001 *$ \\
\hline Lumbar disc displacement $\uparrow$ & $0 \%$ & $62.5 \%$ & $<0.001 *$ \\
\hline Cervical disc degeneration $\dagger$ & $32.5 \%$ & $46.2 \%$ & 0.214 \\
\hline $\operatorname{CCL5}(\mathrm{ng} / \mathrm{mL})$ & $\begin{array}{c}12.8( \pm 7.7) \\
2.1-33.0\end{array}$ & $\begin{array}{c}19.8( \pm 13.0) \\
2.1-63.8\end{array}$ & $0.015^{*}$ \\
\hline CXCL6 (pg/mL) & $\begin{array}{c}43.4( \pm 18.4) \\
16.7-91.6\end{array}$ & $\begin{array}{c}56.9( \pm 26.2) \\
18.6-150.5\end{array}$ & $0.010^{*}$ \\
\hline
\end{tabular}

$\dagger$ Categorical variables denoted as mean \pm SD (range). DDD, degenerative disc disease.

$* p \leq 0.05$ denotes statistical significant difference

degeneration and moderate/severe disc degeneration groups.

\section{Discussion}

The results of this study demonstrate for the first time in humans that significantly elevated levels of systemic blood plasma concentrations of distinct chemokines CCL5 and CXCL6 were noted in individuals with moderate/severe disc degeneration in comparison to a control group with no signs of disc degeneration on MRI. Importantly, the study subjects were matched for age, sex, BMI and workload, so that any influence of these parameters on the outcome can be excluded/minimised. Our findings further substantiate our previous work as well as that of others based on animal models and human extracted symptomatic disc tissue that CCL5 and CXCL6 are associated with clinically-relevant degenerated disc. Therefore, systemic CCL5 and CXCL6 levels might be considered as molecular "biomarkers" for the diagnosis and monitoring of clinically-relevant disc disease.

Serological analyses have several advantages among diagnostic tools; they are non-invasive, simple, convenient, quantitative and reproducible. In the case of disc degeneration, the quantitative and objective data obtained by serological tests may be valuable for complementing image-based assessments. Conventional imaging reflects a condition of disc-related changes that occurred in the past, while assessment of current activity of the disease is restricted. In contrast, the measurement of circulating biomarkers provides the potential for monitoring disease state, progression or treatment effectiveness.
Potential circadian variations need to be taken into consideration when comparing plasma chemokine levels, although there is limited information available from the literature. A recent study with 30 healthy aging subjects found that blood plasma levels of most inflammatory mediators were increased when the blood was taken in the afternoon compared to samples drawn in the morning (Altara et al., 2015). While this increase was not significant for CCL5, CXCL6 was not assessed in that study. Nevertheless, the potential of diurnal changes in chemokine levels underlines the importance of a standardised blood sampling protocol as applied in the present study.

A panel of biomarkers has been developed with the potential to monitor severity, activity and progression of arthritic diseases such as osteoarthritis (OA) and rheumatoid arthritis (RA) (Mabey and Honsawek, 2015). Such markers of matrix breakdown, matrix synthesis, or inflammation are detectable in synovial fluid and in the peripheral blood of patients with acute or chronic disorders of the synovial joint. A recent review of the different cytokines considered as biochemical markers for osteoarthritis revealed IL-6 as a potential diagnostic and prognostic marker, whereas other cytokines such as IL-1 $\beta$, TNF- $\alpha$, IL-15 and VEGF were associated with the disease burden (Mabey and Honsawek, 2015). It has been suggested that inflammatory biomarkers may play a role in identifying subgroups of OA patients with different disease progression rates; this may allow the clinician to differentiate phenotypes within a heterogeneous population and to adjust the treatment accordingly (Attur et al., 2013).

The inflammatory chemokine CCL5 has been investigated in several studies addressing arthritic diseases. CCL5 is produced by articular chondrocytes, and its 
Fig. 2. Error bars illustrating means and $95 \%$ confidence levels of systemic blood plasma concentrations of (a) CCL5 (ng/ $\mathrm{mL})$ and (b) CXCL6 (pg/mL) in patients with no disc degeneration (control group) and those with disc degeneration (degenerated group). $p=0.015$ (a) and $p=0.010$ (b) denote statistical significant difference.
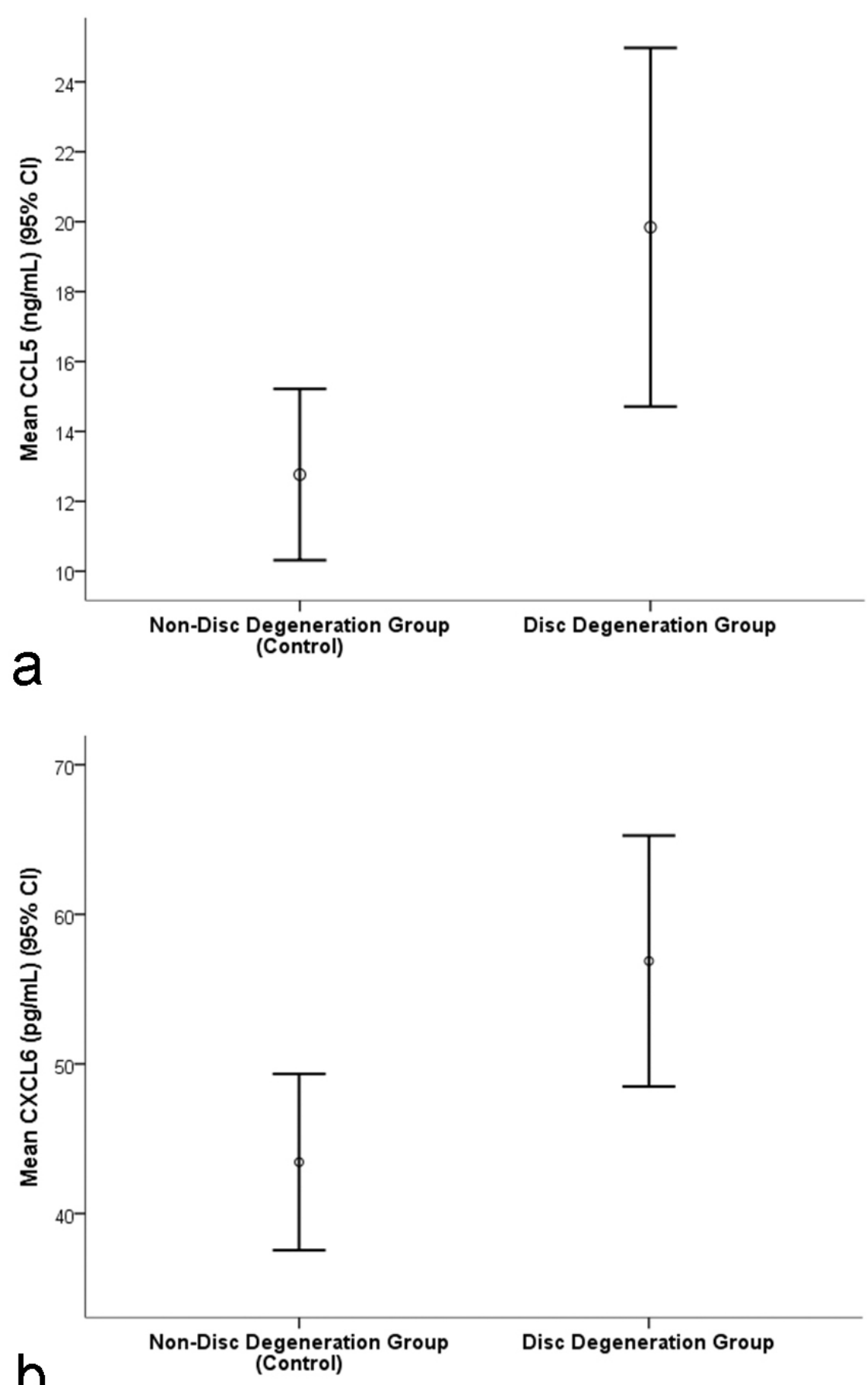

production can be up-regulated by the pro-inflammatory cytokines IL-1 and TNF- $\alpha$ (Pulsatelli et al., 1999). Progressive RA has been associated with increased serum values of CCL5, while serum CCL5 was responsive to methotrexate treatment (Boiardi et al., 1999). Specific histological variants of synovitis have been correlated with varying serum concentrations of CCL5 in RA patients and could reflect the clinical activity of the disease (Klimiuk et al., 2005). Torikai et al. (2007) also reported that CCL5 serum levels were significantly increased in RA patients compared with normal volunteers, although treatment with anti-inflammatory infliximab did not affect CCL5 concentration. Furthermore, active but not inactive state of OA was associated with elevated serum levels of TNF- $\alpha$, IL-6 and CCL5 (Toncheva et al., 2009). More recently, CCL5 has been recognised as a chemotactic mediator produced by intervertebral disc cells. In an organ culture model, this chemokine has been identified as a key factor mediating stem cell recruitment in induced degenerative discs (Pattappa et al., 2014). Kepler et al. (2013) found increased expression of CCL5 in painful disc disease, whereby its expression was enhanced with increasing disc degeneration grade. Moreover, CCL5 expression was correlated with increased levels of the inflammatory cytokine IL-1 $\beta$ and could be induced by IL-1 $\beta$ and TNF- $\alpha$ in vitro (Gruber et al., 2014; Kepler et al., 2013). Histological observations further corroborated the presence of this chemokine in human intervertebral discs (Gruber et al., 2014; Pattappa et al., 2014). In a cohort of older adults with LBP, a correlation was found 
Fig. 3. Receiver operating characteristics curve noting the area under the curve for CCL5 and CXCL6 in relation to the presence of disc degeneration.

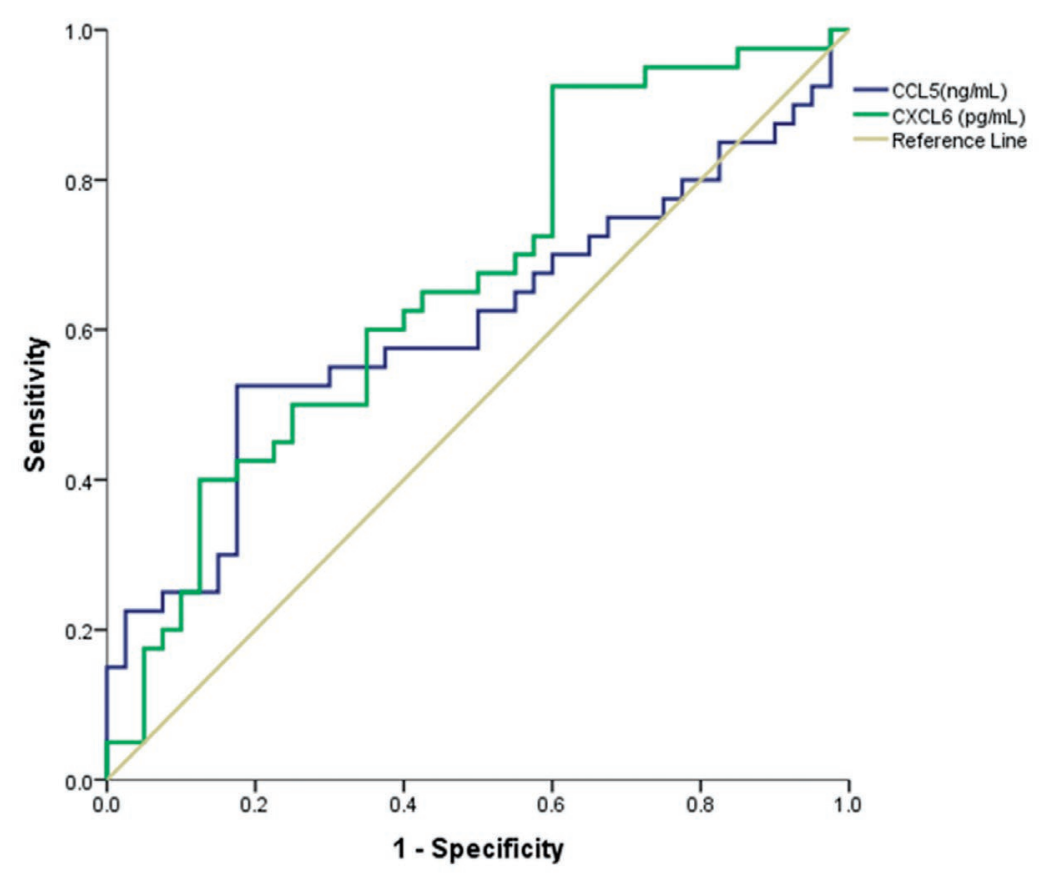

between pain and pain-related functions and circulating concentrations of CCL5 (Sowa et al., 2014). It was concluded that this biomarker may be used for assessment of the disease state in older adults, where imaging changes are omnipresent (Sowa et al., 2014). The present study adds to these previous observations the important finding of a demarcation in plasma levels between subjects with disc degeneration and non-degenerative matched control subjects. Systemic CCL5 values exceeding a certain physiological concentration may thus also contribute to the diagnosis of a degenerative disc state in patients younger than 60 years. Furthermore, the present study revealed a trend towards higher CCL5 levels in DDD patients with disc displacement compared to DDD patients without disc displacement. This observation is further supported by the increased chemokine levels often associated with structural and morphological disc alterations.

The chemokine CXCL6, also known as granulocyte chemotactic protein 2 (GCP2), has been less intensely investigated. Among a panel of various cytokines and chemokines, CXCL6 can be induced in chondrocytes in response to IL-1 $\beta$ (Sandell et al., 2008). CXCL6 has been identified, in addition to CCL5, in fibroblast cells of RA patients and is significantly up-regulated by tolllike receptor stimulation (Pierer et al., 2004). In OA chondrocytes, IL-1 mediated expression of CXCL6 can be suppressed by the polyphenol epigallocatechin-3-gallate, demonstrating its responsiveness to anti-inflammatory treatment (Akhtar and Haqqi, 2011). CXCL6 has been detected in conditioned medium of intervertebral discs in organ culture and may contribute to the chemotactic response of induced-degenerative discs (Pattappa et al., 2014). The finding of elevated circulating levels of CXCL6 in patients with disc degeneration is novel and may lead to more specific diagnostic possibilities in the area of disc diseases. Furthermore, in our current study, CXCL6 seems to be slightly more predictive or associated with moderate/ severe disc degeneration that CCL5 as noted by the ROC analyses.

It has been reported that human NP and AF tissues as well as human organ cultured whole degenerative discs release CCL5 (Krock et al., 2014; Li et al., 2005); while CCL5 and CXCL6 were secreted by induced degenerative whole discs with endplates (Pattappa et al., 2014). We therefore hypothesise that in moderately to severely degenerative lumbar discs these chemokines actively diffuse through the endplate and the annulus fibrosus, along with an increased nerve and vessel ingrowth in degenerative discs (Krock et al., 2014). Through this mechanism increased amounts of cytokines may be detectable in the circulation even if they arise from a nonvascularised tissue. Furthermore, CCL5 and CXCL6 were also detected in the blood plasma of subjects with no disc degeneration. This is consistent with the physiological functions of these cytokines as chemotactic and activating factors of immune cells, further stressing their major roles in immune responses.

Naturally, there were some limitations associated with this study. Although we noted elevated chemokine levels in individuals with moderate/severe lumbar disc degeneration, it remains unknown if indeed these levels represent activity in the discs or active inflammation in peripheral regions of the body. Nonetheless, from our understanding, we did not note any evidence that subjects may have coexisting conditions that may confound the sensitivity of the biomarkers in this setting and in addition did not seem to be related to the presence of disc degeneration in other spine regions. Furthermore, we attempted to account for all potential co-morbidities at the time of recruitment. The prevalence of reported co-morbidities in our study sample was not prominent, because these were volunteer individuals from the population and not patient-based, 
whereby a higher prevalence of co-morbidities would exist. Furthermore, our understanding of these biomarkers is still relatively new. We hope that our current study, which is the first to find an association between systematic biomarkers and stages of disc degeneration on MRI, would provide further credence for future studies to assess extraneous factors that may affect these chemokines in relation to spine degeneration.

Also, although our AUC values were not relatively high in relation to disc degeneration, this may be influenced by the range of degenerative scores, the phenotype sensitivity of disc degeneration on traditional T2W MRI, sample size, and the fact that our cohort samples were drawn from the population and were not patient-based that typically may present with extensive disc changes. Nonetheless, it is not uncommon for even other clinical biomarkers in current clinical use, such as those used to detect prostate and bladder cancer among others, to have similar AUC values (Glas et al., 2003). Importantly, our findings that systemic blood levels of CCL5 and CXCL6 were significantly elevated in subjects with disc degeneration further support our previous work (Illien-Junger et al., 2012; Pattappa et al., 2014) and that of others (Kepler et al., 2013) noting similar chemokine changes in human degenerated disc tissue. Furthermore, we employed a case-control approach whereby both groups were matched for modifiable and non-modifiable risk factors to allow direct comparisons of the chemokine levels between groups. Although the sample size in each group was modest, excellent statistical power calculations were noted. Moreover, our subjects represent a homogenous population and ethnic variations may exist that may affect the generalisability of the findings. However, such homogeneity is an advantage in this case to avoid potential confounding with ethnicity in studies. That said, our findings provide the foundation that systemic blood chemokine levels may exist that are implicated with clinically-relevant disc degeneration but require further replication in other ethnic cohorts. Future large, prospective studies are further needed to assess the clinical utility of these biomarkers and their influence upon clinical decision-making.

\section{Conclusions}

Our study is the first to note in humans that elevated systemic blood plasma levels of CCL5 and CXCL6 are associated with moderate/severe lumbar disc degeneration on MRI. These chemokines might provide valuable information about the degenerative state of an intervertebral disc in addition to structural/morphological findings observed on imaging. Moreover, the findings further contribute to our understanding of the degenerative process, and may eventually lead to new diagnostic and therapeutic options. Further studies will be required to assess the validity of systemic CCL5 and CXCL6 levels for identifying discogenic related LBP, monitoring disease progression and/or treatment effects, as well as for replication in other populations.

\section{Acknowledgements}

The authors thank the Hong Kong Jockey Club MRI center and the Hong Kong Sanatorium and Hospitals for the utilisation of their MRI facilities. The authors also wish to thank Ms. Pei Yu of the Department of Biochemistry, The University of Hong Kong for her technical assistance. This work was supported by grants from the University Grants Committee of Hong Kong, the Area of Excellence Scheme (AoE/M-04/04), the Hong Kong Theme-Based Research Scheme (T12-708/12N) and AOSpine International. We wish to confirm that there are no known conflicts of interest associated with this publication and there has been no significant financial support for this work that could have influenced its outcome.

\section{References}

Akhtar N, Haqqi TM (2011) Epigallocatechin-3gallate suppresses the global interleukin-1beta-induced inflammatory response in human chondrocytes. Arthritis Res Ther 13: R93.

Altara R, Manca M, Hermans KC, Daskalopoulos EP, Brunner-La Rocca HP, Hermans RJ, Struijker-Boudier HA, Blankesteijn MW (2015) Diurnal rhythms of serum and plasma cytokine profiles in healthy elderly individuals assessed using membrane based multiplexed immunoassay. J Transl Med 13: 129.

Andersson GB (1999) Epidemiological features of chronic low-back pain. Lancet 354: 581-585.

Attur M, Krasnokutsky-Samuels S, Samuels J, Abramson SB (2013) Prognostic biomarkers in osteoarthritis. Curr Opin Rheumatol 25: 136-144.

Boden SD, Davis DO, Dina TS, Patronas NJ, Wiesel SW (1990) Abnormal magnetic-resonance scans of the lumbar spine in asymptomatic subjects. A prospective investigation. J Bone Joint Surg Am 72: 403-408.

Boiardi L, Macchioni P, Meliconi R, Pulsatelli L, Facchini A, Salvarani C (1999) Relationship between serum RANTES levels and radiological progression in rheumatoid arthritis patients treated with methotrexate. Clin Exp Rheumatol 17: 419-425.

Borenstein DG, O'Mara JW, Jr., Boden SD, Lauerman WC, Jacobson A, Platenberg C, Schellinger D, Wiesel SW (2001) The value of magnetic resonance imaging of the lumbar spine to predict low-back pain in asymptomatic subjects : a seven-year follow-up study. J Bone Joint Surg Am 83: 1306-1311.

Burke JG, Watson RW, McCormack D, Dowling FE, Walsh MG, Fitzpatrick JM (2002) Intervertebral discs which cause low back pain secrete high levels of proinflammatory mediators. J Bone Joint Surg Br 84: 196201.

Carragee EJ, Don AS, Hurwitz EL, Cuellar JM, Carrino JA, Herzog R (2009) Does discography cause accelerated progression of degeneration changes in the lumbar disc: a ten-year matched cohort study. Spine 34: 2338-2345.

Cheung KM, Karppinen J, Chan D, Ho DW, Song YQ, Sham P, Cheah KS, Leong JC, Luk KD (2009) Prevalence 
and pattern of lumbar magnetic resonance imaging changes in a population study of one thousand forty-three individuals. Spine 34: 934-940.

Cheung KM, Samartzis D, Karppinen J, Mok FP, Ho DW, Fong DY, Luk KD (2010) Intervertebral disc degeneration: new insights based on "skipped" level disc pathology. Arthritis Rheum 62: 2392-2400.

Cheung KM, Samartzis D, Karppinen J, Luk KD (2012) Are "patterns" of lumbar disc degeneration associated with low back pain?: new insights based on skipped level disc pathology. Spine 37: E430-438.

Chou D, Samartzis D, Bellabarba C, Patel A, Luk KD, Kisser JM, Skelly AC (2011) Degenerative magnetic resonance imaging changes in patients with chronic low back pain: a systematic review. Spine 36: S43-53.

Dagenais S, Caro J, Haldeman S (2008) A systematic review of low back pain cost of illness studies in the United States and internationally. Spine J 8: 8-20.

Deyo RA, Gray DT, Kreuter W, Mirza S, Martin BI (2005) United States trends in lumbar fusion surgery for degenerative conditions. Spine 30: 1441-1445.

Fardon DF, Williams AL, Dohring EJ, Murtagh FR, Gabriel Rothman SL, Sze GK (2014) Lumbar disc nomenclature: version 2.0: Recommendations of the combined task forces of the North American Spine Society, the American Society of Spine Radiology and the American Society of Neuroradiology. Spine J 14: 2525-2545.

Fenty M, Crescenzi R, Fry B, Squillante D, Turk D, Maurer PM, Borthakur A (2013) Novel imaging of the intervertebral disk and pain. Global Spine J 3: 127-132.

Freemont AJ (2009) The cellular pathobiology of the degenerate intervertebral disc and discogenic back pain. Rheumatology 48: 5-10.

Fritzell P, Hagg O, Wessberg P, Nordwall A (2002) Chronic low back pain and fusion: a comparison of three surgical techniques: a prospective multicenter randomized study from the Swedish lumbar spine study group. Spine 27: 1131-1141.

Glas AS, Roos D, Deutekom M, Zwinderman AH, Bossuyt PM, Kurth KH (2003) Tumor markers in the diagnosis of primary bladder cancer. A systematic review. J Urol 169: 1975-1982.

Goode AP, Marshall SW, Kraus VB, Renner JB, Sturmer T, Carey TS, Irwin DE, Jordan JM (2012) Association between serum and urine biomarkers and lumbar spine individual radiographic features: the Johnston County Osteoarthritis Project. Osteoarthritis Cartilage 20: 1286-1293.

Gruber HE, Hoelscher GL, Ingram JA, Bethea S, Norton HJ, Hanley EN, Jr. (2014) Production and expression of RANTES (CCL5) by human disc cells and modulation by IL-1-beta and TNF-alpha in 3D culture. Exp Mol Pathol 96: 133-138.

Illien-Junger S, Pattappa G, Peroglio M, Benneker LM, Stoddart MJ, Sakai D, Mochida J, Grad S, Alini M (2012) Homing of mesenchymal stem cells in induced degenerative intervertebral discs in a whole organ culture system. Spine 37: 1865-1873.

Jensen MC, Brant-Zawadzki MN, Obuchowski N, Modic MT, Malkasian D, Ross JS (1994) Magnetic resonance imaging of the lumbar spine in people without back pain. N Engl J Med 331: 69-73.

Kepler CK, Markova DZ, Dibra F, Yadla S, Vaccaro AR, Risbud MV, Albert TJ, Anderson DG (2013) Expression and relationship of proinflammatory chemokine RANTES/CCL5 and cytokine IL-1beta in painful human intervertebral discs. Spine 38: 873-880.

Klimiuk PA, Sierakowski S, Latosiewicz R, Skowronski J, Cylwik JP, Cylwik B, Chwiecko J (2005) Histological patterns of synovitis and serum chemokines in patients with rheumatoid arthritis. J Rheumatol 32: 1666-1672.

Krock E, Rosenzweig DH, Chabot-Dore AJ, Jarzem P, Weber MH, Ouellet JA, Stone LS, Haglund L (2014) Painful, degenerating intervertebral discs up-regulate neurite sprouting and CGRP through nociceptive factors. J Cell Mol Med 18: 1213-1225.

Li H, Zou X, Baatrup A, Lind M, Bunger C (2005) Cytokine profiles in conditioned media from cultured human intervertebral disc tissue. Implications of their effect on bone marrow stem cell metabolism. Acta Orthop 76: 115-121.

Lotz JC, Haughton V, Boden SD, An HS, Kang JD, Masuda K, Freemont A, Berven S, Sengupta DK, Tanenbaum L, Maurer P, Ranganathan A, Alavi A, Marinelli NL (2012) New treatments and imaging strategies in degenerative disease of the intervertebral disks. Radiology 264: 6-19.

Mabey T, Honsawek S (2015) Cytokines as biochemical markers for knee osteoarthritis. World J Orthop 6: 95-105.

Mok FP, Samartzis D, Karppinen J, Luk KD, Fong DY, Cheung KM (2010) Prevalence, determinants, and association of schmorl nodes of the lumbar spine with disc degeneration: A population-based study of 2449 individuals. Spine 35: 1944-1952.

Pattappa G, Peroglio M, Sakai D, Mochida J, Benneker LM, Alini M, Grad S (2014) CCL5/RANTES is a key chemoattractant released by degenerative intervertebral discs in organ culture. Eur Cell Mater 27: 124-136.

Pierer M, Rethage J, Seibl R, Lauener R, Brentano F, Wagner U, Hantzschel H, Michel BA, Gay RE, Gay S, Kyburz D (2004) Chemokine secretion of rheumatoid arthritis synovial fibroblasts stimulated by Toll-like receptor 2 ligands. J Immunol 172: 1256-1265.

Pulsatelli L, Dolzani P, Piacentini A, Silvestri T, Ruggeri R, Gualtieri G, Meliconi R, Facchini A (1999) Chemokine production by human chondrocytes. J Rheumatol 26: 19922001.

Rajaee SS, Bae HW, Kanim LE, Delamarter RB (2011) Spinal fusion in the United States: Analysis of trends from 1998 to 2008. Spine 37: 67-76.

Rannou F, Ouanes W, Boutron I, Lovisi B, Fayad F, Mace Y, Borderie D, Guerini H, Poiraudeau S, Revel M (2007) High-sensitivity C-reactive protein in chronic low back pain with vertebral end-plate Modic signal changes. Arthritis Rheum 57: 1311-1315.

Rathod TN, Chandanwale A, Ladkat KM, Chavan S, Chavan A, Bhosale PB (2014) High sensitive C-reactive protein-Effective tool in determining postoperative recovery in lumbar disc disease. Indian J Orthop 48: 354359. 
Roy RA, Boucher JP, Comtois AS (2010) Inflammatory response following a short-term course of chiropractic treatment in subjects with and without chronic low back pain. J Chiropr Med 9: 107-114.

Samartzis D, Karppinen J, Mok F, Fong DY, Luk KD, Cheung KM (2011) A population-based study of juvenile disc degeneration and its association with overweight and obesity, low back pain, and diminished functional status. J Bone Joint Surg Am 93: 662-670.

Samartzis D, Karppinen J, Chan D, Luk KD, Cheung KM (2012) The association of lumbar intervertebral disc degeneration on magnetic resonance imaging with body mass index in overweight and obese adults: a populationbased study. Arthritis Rheum 64: 1488-1496.

Samartzis D, Borthakur A, Belfer I, Bow CH, Lotz JC, Wang H-Q, Cheung KMC, Carragee E, Karppinen J (2015) Novel diagnostic and therapeutic methods for intervertebral disc degeneration and low back pain. Spine J 15: 1919-1932.

Sandell LJ, Xing X, Franz C, Davies S, Chang LW, Patra D (2008) Exuberant expression of chemokine genes by adult human articular chondrocytes in response to IL1beta. Osteoarthritis Cartilage 16: 1560-1571.

Schneiderman G, Flannigan B, Kingston S, Thomas J, Dillin WH, Watkins RG (1987) Magnetic resonance imaging in the diagnosis of disc degeneration: correlation with discography. Spine 12: 276-281.

Shen FH, Samartzis D, Andersson GB (2006) Nonsurgical management of acute and chronic low back pain. J Am Acad Orthop Surg 14: 477-487.

Song YQ, Cheung KM, Ho DW, Poon SC, Chiba K, Kawaguchi Y, Hirose Y, Alini M, Grad S, Yee AF, Leong JC, Luk KD, Yip SP, Karppinen J, Cheah KS, Sham P, Ikegawa S, Chan D (2008) Association of the asporin D14 allele with lumbar-disc degeneration in Asians. Am J Hum Genet 82: 744-747.

Sowa GA, Perera S, Bechara B, Agarwal V, Boardman J, Huang W, Camacho-Soto A, Vo N, Kang J, Weiner D (2014) Associations between serum biomarkers and pain and pain-related function in older adults with low back pain: a pilot study. J Am Geriatr Soc 62: 2047-2055.

Takatalo J, Karppinen J, Niinimaki J, Taimela S, Nayha S, Mutanen P, Sequeiros RB, Kyllonen E, Tervonen O (2011) Does lumbar disc degeneration on magnetic resonance imaging associate with low back symptom severity in young Finnish adults? Spine 36: 2180-2189.

Toncheva A, Remichkova M, Ikonomova K, Dimitrova P, Ivanovska N (2009) Inflammatory response in patients with active and inactive osteoarthritis. Rheumatol Int 29: 1197-1203.

Torikai E, Kageyama Y, Suzuki M, Ichikawa T, Nagano A (2007) The effect of infliximab on chemokines in patients with rheumatoid arthritis. Clin Rheumatol 26: 1088-1093.

Vavken P, Ganal-Antonio AK, Shen FH, Chapman JR, Samartzis D (2015) Fundamentals of clinical outcomes assessment for spinal disorders: study designs, methodologies, and analyses. Global Spine J 5: 156-164.

Vos T, Flaxman AD, Naghavi M, Lozano R, Michaud C, Ezzati M, Shibuya K, Salomon JA, Abdalla S, Aboyans V, Abraham J, Ackerman I, Aggarwal R, Ahn SY, Ali MK, Alvarado M, Anderson HR, Anderson LM, Andrews KG,
Atkinson C, Baddour LM, Bahalim AN, Barker-Collo S, Barrero LH, Bartels DH, Basanez MG, Baxter A, Bell ML, Benjamin EJ, Bennett D, Bernabe E, Bhalla K, Bhandari B, Bikbov B, Bin Abdulhak A, Birbeck G, Black JA, Blencowe H, Blore JD, Blyth F, Bolliger I, Bonaventure A, Boufous S, Bourne R, Boussinesq M, Braithwaite T, Brayne C, Bridgett L, Brooker S, Brooks P, Brugha TS, Bryan-Hancock C, Bucello C, Buchbinder R, Buckle G, Budke CM, Burch M, Burney P, Burstein R, Calabria B, Campbell B, Canter CE, Carabin H, Carapetis J, Carmona L, Cella C, Charlson F, Chen H, Cheng AT, Chou D, Chugh SS, Coffeng LE, Colan SD, Colquhoun S, Colson KE, Condon J, Connor MD, Cooper LT, Corriere M, Cortinovis M, de Vaccaro KC, Couser W, Cowie BC, Criqui MH, Cross M, Dabhadkar KC, Dahiya M, Dahodwala N, DamsereDerry J, Danaei G, Davis A, De Leo D, Degenhardt L, Dellavalle R, Delossantos A, Denenberg J, Derrett S, Des Jarlais DC, Dharmaratne SD, Dherani M, Diaz-Torne C, Dolk H, Dorsey ER, Driscoll T, Duber H, Ebel B, Edmond K, Elbaz A, Ali SE, Erskine H, Erwin PJ, Espindola P, Ewoigbokhan SE, Farzadfar F, Feigin V, Felson DT, Ferrari A, Ferri CP, Fevre EM, Finucane MM, Flaxman S, Flood L, Foreman K, Forouzanfar MH, Fowkes FG, Franklin R, Fransen M, Freeman MK, Gabbe BJ, Gabriel SE, Gakidou E, Ganatra HA, Garcia B, Gaspari F, Gillum RF, Gmel G, Gosselin R, Grainger R, Groeger J, Guillemin F, Gunnell D, Gupta R, Haagsma J, Hagan H, Halasa YA, Hall W, Haring D, Haro JM, Harrison JE, Havmoeller R, Hay RJ, Higashi H, Hill C, Hoen B, Hoffman H, Hotez PJ, Hoy D, Huang JJ, Ibeanusi SE, Jacobsen KH, James SL, Jarvis D, Jasrasaria R, Jayaraman S, Johns N, Jonas JB, Karthikeyan G, Kassebaum N, Kawakami N, Keren A, Khoo JP, King CH, Knowlton LM, Kobusingye O, Koranteng A, Krishnamurthi R, Lalloo R, Laslett LL, Lathlean T, Leasher JL, Lee YY, Leigh J, Lim SS, Limb E, Lin JK, Lipnick M, Lipshultz SE, Liu W, Loane M, Ohno SL, Lyons R, Ma J, Mabweijano J, MacIntyre MF, Malekzadeh R, Mallinger L, Manivannan S, Marcenes W, March L, Margolis DJ, Marks GB, Marks R, Matsumori A, Matzopoulos R, Mayosi BM, McAnulty JH, McDermott MM, McGill N, McGrath J, Medina-Mora ME, Meltzer M, Mensah GA, Merriman TR, Meyer AC, Miglioli V, Miller M, Miller TR, Mitchell PB, Mocumbi AO, Moffitt TE, Mokdad AA, Monasta L, Montico M, Moradi-Lakeh M, Moran A, Morawska L, Mori R, Murdoch ME, Mwaniki MK, Naidoo K, Nair MN, Naldi L, Narayan KM, Nelson PK, Nelson RG, Nevitt MC, Newton CR, Nolte S, Norman P, Norman R, O’Donnell M, O'Hanlon S, Olives C, Omer SB, Ortblad K, Osborne R, Ozgediz D, Page A, Pahari B, Pandian JD, Rivero AP, Patten SB, Pearce N, Padilla RP, Perez-Ruiz F, Perico N, Pesudovs K, Phillips D, Phillips MR, Pierce K, Pion S, Polanczyk GV, Polinder S, Pope CA, 3rd, Popova S, Porrini E, Pourmalek F, Prince M, Pullan RL, Ramaiah KD, Ranganathan D, Razavi H, Regan M, Rehm JT, Rein DB, Remuzzi G, Richardson K, Rivara FP, Roberts T, Robinson C, De Leon FR, Ronfani L, Room R, Rosenfeld LC, Rushton L, Sacco RL, Saha S, Sampson U, Sanchez-Riera L, Sanman E, Schwebel DC, Scott JG, Segui-Gomez M, Shahraz S, Shepard DS, Shin H, Shivakoti R, Singh D, Singh GM, Singh JA, Singleton J, Sleet DA, Sliwa K, Smith E, Smith JL, Stapelberg NJ, 
Steer A, Steiner T, Stolk WA, Stovner LJ, Sudfeld C, Syed S, Tamburlini G, Tavakkoli M, Taylor HR, Taylor JA, Taylor WJ, Thomas B, Thomson WM, Thurston GD, Tleyjeh IM, Tonelli M, Towbin JA, Truelsen T, Tsilimbaris MK, Ubeda C, Undurraga EA, van der Werf MJ, van Os J, Vavilala MS, Venketasubramanian N, Wang M, Wang W, Watt K, Weatherall DJ, Weinstock MA, Weintraub R, Weisskopf MG, Weissman MM, White RA, Whiteford H, Wiersma ST, Wilkinson JD, Williams HC, Williams SR, Witt E, Wolfe F, Woolf AD, Wulf S, Yeh PH, Zaidi AK, Zheng ZJ, Zonies D, Lopez AD, Murray CJ, AlMazroa MA, Memish ZA (2012) Years lived with disability (YLDs) for 1160 sequelae of 289 diseases and injuries 1990-2010: a systematic analysis for the Global Burden of Disease Study 2010. Lancet 380: 2163-2196.

Wuertz K, Haglund L (2013) Inflammatory mediators in intervertebral disk degeneration and discogenic pain. Global Spine J 3: 175-184.

Zhang YG, Guo TM, Guo X, Wu SX (2009) Clinical diagnosis for discogenic low back pain. Int J Biol Sci 5: 647-658.

\section{Discussion with Reviewer}

Reviewer III: The authors have attempted to correlate increases in specific biomarkers with the secondary degeneration phenotype of disc deformation. What do they propose as the underlying pathomechanism to link these two?

Authors: Disc displacement, defined as presence of posterior disc bulge, protrusion or extrusion, is likely to also affect adjacent structures of the disc, such as soft tissues, neural tissues and ligaments. For this reason it was hypothesised that the presence of disc displacement may lead to a more pronounced inflammatory reaction as compared to disc degeneration without displacement, resulting in higher levels of secreted chemokines. The observed trend of increased CCL5 plasma concentrations in subjects with disc displacement partially confirms this suggestion. Further studies with increased sample sizes for all study groups will provide more insight in the correlation between chemokine concentrations and disc displacement.

Editor's Note: Scientific Editor in charge of the paper: Stephen Ferguson. 